\title{
Outcomes of Breast Conservation Surgery and Modified Radical Mastectomy After Neoadjuvant Chemotherapy in Patients with Locally Advanced Breast Cancer
}

\author{
Mohammad Esmaeil Akbari (iD ${ }^{1}$, Belal Delshad ${ }^{1,{ }^{*}}$ and Mostafa Mousavizadeh ${ }^{1}$ \\ ${ }^{1}$ Cancer Research Center (CRC), Shahid Beheshti University of Medical Sciences, Tehran, Iran \\ "Corresponding author: Cancer Research Center(CRC), Shahid Beheshti University of Medical Sciences, Tehran, Iran. Email: dr.belal.delshad@gmail.com
}

Received 2017 May 30; Revised 2019 December 29; Accepted 2019 December 31.

\begin{abstract}
Background: Breast cancer is the most common cancer among Iranian women. The treatment of locally advanced breast cancer (LABC) is an important issue in ongoing studies. There is controversy about the ideal treatment in available studies.

Objectives: We aimed at comparing the local recurrence rate and disease-free survival in patients with LABC in breast-conserving therapy (BCT) and modified radical mastectomy (MRM) groups after neoadjuvant chemotherapy.

Methods: In this cohort, we analyzed the data of patients with LABC referred to the cancer research center of Shohada-E-Tajrish Hospital. Patients were categorized into two groups of BCT and MRM. Different parameters were recorded and compared between the two groups. Endpoint outcome measures were defined as survival rate and local recurrence rate.

Results: Generally, 115 patients with an average age of 48.23 years in BCT and 48.76 years in the MRM group were included. Hormone consumption history showed a significant difference between the two surgery groups $(\mathrm{P}=0.032)$. Twenty-one patients $(18.26 \%)$ showed local recurrence. The disease-free survival rate did not differ between the two surgery groups $(\mathrm{P}=0.250)$. The association of survival was only significant with cigarette smoking $(P=0.041)$.

Conclusions: BCT after neoadjuvant chemotherapy showed an identical disease-free survival rate compared to MRM and did not show lower survival or higher recurrence rate in comparison to radical mastectomy.
\end{abstract}

Keywords: Breast Neoplasms, Breast-Conserving Surgery, Modified Radical Mastectomy, Disease-Free Survival, Survival Analysis

\section{Background}

Cancer is the second leading cause of death throughout the world $(1,2)$ and its burden has doubled within the last 30 years (2). Breast cancer is the most common type of cancer accounting for $23 \%$ of all cancers (3), which ranks third in the most lethal malignancies among women $(2,4)$. Generally, $16 \%$ of cancer deaths are due to breast cancer (1); therefore, breast cancer is known as a major health problem in the world. In Iran, breast cancer is the most prevalent cancer among women $(5,6)$, accounting for $24.4 \%$ of all malignancies (7) and its crude incidence has been 17.81 (6).

Locally advanced breast cancer (LABC) is a subset of breast cancer characterized by the most advanced breast tumors in the absence of distant metastasis. To be more precise, recent guidelines of U.S. National Comprehensive Cancer Network have described LABC as fulfilling any of the following criteria without the presence of distant metastasis (8): tumors more than $5 \mathrm{~cm}$ in size with re- gional lymphadenopathy (N1-3), tumors of any size with direct extension to the chest wall or skin, or both (including ulcer or satellite nodules) regardless of regional lymphadenopathy, the presence of regional lymphadenopathy (clinically fixed or matted axillary lymph nodes, or any of infraclavicular, supraclavicular, or internal mammary lymphadenopathy) regardless of tumor stage.

Today, LABC is managed with a combination of surgery, radiation therapy, and chemotherapy. The treatment sequence usually starts with neoadjuvant chemotherapy to shrink the tumors in the breast and lymph nodes, thereby facilitating performing surgery with better outcomes. The surgery type in LABC is usually modified radical mastectomy (MRM), but an increasing rate of patients request breast-conserving therapy (BCT) due to various reasons, mainly cosmetic issues, which of course plays an important role in the quality of life maintenance in patients (9). 


\section{Objectives}

In this study, we aimed at comparing the outcomes of MRM and BCT regarding local recurrence rate and disease-free survival in patients with LABC after neoadjuvant chemotherapy.

\section{Methods}

In the present study, patients with LABC previously undergoing neoadjuvant chemotherapy referred to the cancer research center of Shohada-E-Tajrish Hospital (Tehran, Iran) between 2013 and 2015 were included. All patients referred to our clinic were included to evaluate the inclusion and exclusion criteria. Patients with: (1) tumor size more than $5 \mathrm{~cm},(2) 4$ or more involved lymph nodes (N2, N3) and (3) stage III were included in the study and categorized into the BCT and MRM groups. Family history, age, tumor markers, oncogenes, tumor suppressor genes, and 1- to 5-year survival were recorded. The exclusion criteria included the presence of distant metastasis, the multifocal lesion in one breast, extensive microcalcification in the breast, and huge tumor size in comparison to breast size, which makes breast-conserving surgery non-feasible, the presence of chemoradiotherapy and hormone therapy contraindications, and considerable skin changes.

Medical records were reviewed and questionnaires were filled out. Phone contact, clinic visits, and paraclinical tests were also conducted. Questionnaires included family history, age, tumor markers, oncogenes, tumor suppressor genes, and 1- to 5-year survival.

Data confidentiality was respected through the study. No individual report was published. Patients' treatment did not alter due to sole research purposes. No additional charge was applied to patients. Prior to enrollment, written informed consent was obtained from all subjects and Shahid Beheshti University of Medical Sciences board of ethics approved the protocol of the study. All procedures regarding human subjects were in accordance with Helsinki Declaration guidelines.

\subsection{Statistical Analysis}

Statistical analyses were performed, using SPSS version 19.0 for Windows (IBM Corporation, New York, United States). Continuous variables are presented as mean \pm standard error of mean and categorical variables as proportions. Baseline variables between BCT and MRM groups of the trial were compared, using independent $t$ test or chi-square. The comparison of disease-free survival across the two treatment groups was based on Kaplan-Meyer estimates, and P values were calculated from non-parametric log-rank tests. To account for potential confounders, analyses of crude log-rank tests were corroborated with Cox regression models accounting for the following predefined potentially confounding variables. In all tests, a P value of less than 0.05 was considered necessary to discard the null hypothesis.

\section{Results}

In general, 115 patients were evaluated in the present study, including 56 patients (48.7\%) in the BCT group and 59 patients (51.3\%) in the MRM group. The mean value of age was $48.23 \pm 1.51$ and $48.76 \pm 1.30$ years in BCT and MRM groups, respectively $(\mathrm{P}=0.79)$. Patients' characteristics before surgery are shown in Table 1.

\begin{tabular}{|c|c|c|c|}
\hline Parameter & BCT & MRM & PValue \\
\hline Breastfeeding duration, mo & $24.83 \pm 4.41$ & $26.33 \pm 4.59$ & 0.85 \\
\hline Follow-up duration, mo & $24.48 \pm 1.13$ & $28.42 \pm 1.03$ & 0.11 \\
\hline Pregnancy times, No. (\%) & & & 0.683 \\
\hline 0 & $25(44.64)$ & $19(32.20)$ & \\
\hline 1 & $2(3.57)$ & $8(13.55)$ & \\
\hline 2 & $13(23.21)$ & $8(13.55)$ & \\
\hline$\geq 3$ & $16(28.57)$ & $24(40.67)$ & \\
\hline Marital status, No. (\%) & & & 0.941 \\
\hline Single & $13(23.21)$ & $13(22.03)$ & \\
\hline Married & $40(71.42)$ & $42(71.18)$ & \\
\hline Divorced & $3(5.35)$ & $4(6.77)$ & \\
\hline Smoking, No. (\%) & $8(14.28)$ & $4(6.77)$ & 0.155 \\
\hline Abortion, No. (\%) & & & 0.171 \\
\hline 1 & $3(5.35)$ & $7(11.86)$ & \\
\hline 2 & $0(0)$ & $3(5.08)$ & \\
\hline 3 & $2(3.57)$ & $1(1.69)$ & \\
\hline Live birth, No. (\%) & & & 0.423 \\
\hline 0 & $26(46.42)$ & $19(32.20)$ & \\
\hline 1 & $3(5.35)$ & $11(18.64)$ & \\
\hline 2 & $13(23.21)$ & $8(13.55)$ & \\
\hline$\geq 3$ & $14(25)$ & $21(35.59)$ & \\
\hline $\begin{array}{l}\text { Family history of breast } \\
\text { cancer, No. (\%) }\end{array}$ & & & 0.951 \\
\hline Absent & $43(76.78)$ & $44(74.57)$ & \\
\hline 1st degree relatives & $5(8.92)$ & $6(10.16)$ & \\
\hline 2nd degree relatives & $8(14.28)$ & $9(15.25)$ & \\
\hline
\end{tabular}

Abbreviations: BCT, breast-conserving therapy; MRM, modified radical mastectomy 
The history of hormone consumption showed a significant difference between the two groups $(\mathrm{P}=0.032)$; there was a positive history of hormone consumption in 18 patients (32.14\%) in the BCT group and 30 patients (50.84\%) in the MRM group. The cancer stage was not significantly different between BCT and MRM groups $(\mathrm{P}=0.551)$. Twentyone $(37.51 \%)$ patients of the BCT group and 19 patients (32.20\%) of the MRM group were in stage II. Thirty-five patients (62.5\%) and 40 (67.79\%) patients were classified as stage III in BCT and MRM groups, respectively.

Hormone receptors' status was not significantly different between the two groups. The details are seen in Table 2.

Table 2. Hormone Receptors' Status in Breast Cancer Patients in BCT and MRM Groups

\begin{tabular}{lccc}
\hline Hormone Status (N) & BCT & MRM & PValue \\
\hline ER (positive/negative) & $40 / 16$ & $43 / 16$ & 0.513 \\
PR(positive/negative) & $35 / 21$ & $30 / 29$ & 0.142 \\
HER2 (positive/negative) & $12 / 44$ & $8 / 51$ & 0.192 \\
P53 (positive/negative) & $7 / 49$ & $12 / 47$ & 0.190 \\
\hline
\end{tabular}

Abbreviations: ER, Estrogen receptor; HER2, human epidermal growth factor receptor 2; PR, progesterone receptor; BCT, breast-conserving therapy; MRM modified radical mastectomy

Recurrence was detected in 21 patients (18.26\%). The average age in non-recurrence and recurrence groups was $48.6 \pm 10.9$ and $47.9 \pm 10.9$ years, respectively $(\mathrm{P}=0.99)$. Follow-up duration was not significantly different between non-recurrence and recurrence groups (26.8 vs. 25 months, $\mathrm{P}=0.940)$.

Hormone receptors' status in two recurrence and nonrecurrence groups are shown in Table 3.

\begin{tabular}{lccc}
\hline \multicolumn{1}{l}{ Table 3. Hormone Receptors' Status in Recurrence and Non-Recurrence Groups } \\
\hline $\begin{array}{l}\text { Hormone Status } \\
(\%)\end{array}$ & $\begin{array}{c}\text { Non-Recurrence, } \\
\% / \%\end{array}$ & Recurrence, \%/\% & P Value \\
\hline $\begin{array}{l}\text { ER(posi- } \\
\text { tive/negative) }\end{array}$ & $71.3 / 28.7$ & $76.2 / 23.8$ & 0.065 \\
$\begin{array}{l}\text { PR(posi- } \\
\text { tive/negative) }\end{array}$ & $55.3 / 44.7$ & $61.9 / 38.1$ & 0.052 \\
$\begin{array}{l}\text { HER2 (posi- } \\
\text { tive/negative) }\end{array}$ & $17 / 78$ & $19 / 81$ & 0.039 \\
$\begin{array}{l}\text { P53 (posi- } \\
\text { tive/negative) }\end{array}$ & $16 / 84$ & $19 / 81$ & 0.039 \\
\hline
\end{tabular}

Abbreviations: ER, estrogen receptor; HER2, human epidermal growth factor receptor 2; PR, progesterone receptor; BCT, breast-conserving therapy; MRM, modified radical mastectomy

The breast cancer stage was significantly different between the two groups. Stage II comprised $37.2 \%$ of nonrecurrence and $23.8 \%$ of recurrence cases $(P=0.052)$. Stage III was seen in $62.8 \%$ of cases of the non-recurrence group and $76.2 \%$ of recurrence group patients $(\mathrm{P}=0.047)$. Hormone intake was positive in $43.6 \%$ and $33.6 \%$ of nonrecurrence and recurrence group patients, respectively ( $P$ $=0.051$ ). As shown in Figure 1, the survival rate was not significantly different between the BCT and MRM groups ( $\mathrm{P}=$ 0.250 ); further analysis correlating other study parameters with survival showed that only smoking is significantly associated with survival $(\mathrm{P}=0.041)$.

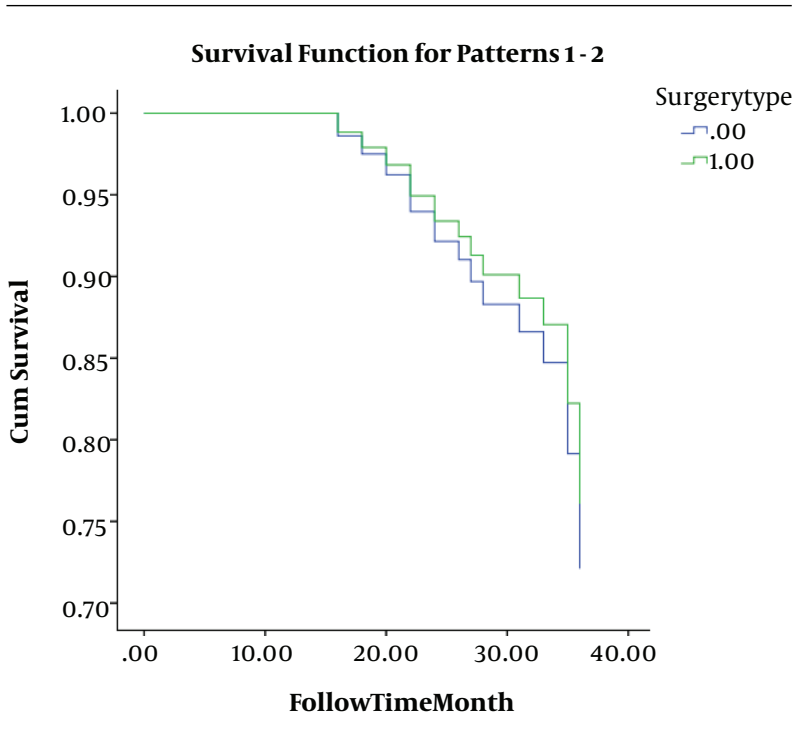

Figure 1. Comparison of overall survival in BCT and MRM groups

\section{Discussion}

Neoadjuvant chemotherapy can lead to the downstaging of the primary tumor. For large tumors that were planned to undergo mastectomy surgery, neoadjuvant chemotherapy has been shown to shrink the tumor and make BCT feasible $(10,11)$. In the current study, the local recurrence rate was compared between patients of BCT and MRM groups after neoadjuvant chemotherapy in patients with LABC. The main challenge in treating patients with LABC with BCT is a concern about the probability of a higher recurrence rate in comparison to the MRM method. It is speculated that tumors treated with neoadjuvant chemotherapy might convert into multicentric segments, which increases the risk of recurrence with the BCT method (12). There was a $21 \%$ recurrence rate in our study, which was not significantly different between the two groups.

In the Nold et al.'s study(13), 55\% of patients had chosen the MRM method and the majority of them said that fear of recurrence is the reason for their choice. In the Lam et al.'s 
study (14), MRM patients mentioned longer survival, lower recurrence, and no need for retreatment.

Touboul et al. $(15,16)$ have evaluated the recurrence rates of both methods in two consecutive years and reported a $16 \%$ to $20 \%$ recurrence rate for BCT and a $5.4 \%$ to $6 \%$ recurrence rate for MRM. This difference did not reach statistical significance. The majority of available reports reveal similar findings except for Lerouge et al.'s study (17) reporting $4 \%$ and $23 \%$ recurrence rates in MRM and BCT groups, respectively, which was significantly different. The survival rate did not differ between the two groups in that study.

The disease-free survival rate was not significantly different between the two groups in our study $(\mathrm{P}=0.250)$. NSABP-B18 (18) has reported a higher local recurrence rate in BCT compared to MRM, but after adjustment for age and tumor size, this significant difference was resolved. Ishitobi et al. (19) could not reveal any significant difference in recurrence-free survival according to surgery type after neoadjuvant chemotherapy. Halverson et al. (20) also emphasized that 5-year survival was 95\% to $100 \%$ either in BCT or MRM regardless of age, grade, or lymph nodes' status. A systematic review in 2016 (21) has reported that 5-year survival was lower in the mastectomy group, but this difference was not statistically significant. Vergine et al. (22) also declared that undergoing neoadjuvant chemotherapy can make BCT as successful as MRM. Contrarily, Shenkier et al. (23) have reported that standard surgery treatment in LABC is MRM and performing BCT is not allowed. Heil et al. (24) have also opposed the recruitment of BCT as standard surgery in LABC cases.

In this study, only 2 hormone receptors were significantly different between recurrence and non-recurrence groups. HER2 and p53 receptors were significantly more prevalent in patients with recurrence; meanwhile, there was no difference between two groups considering ER and PR. Sweeting et al. (25) have reported that the HER2 receptor was present in $24 \%$ of patients with recurrence and $13.1 \%$ of patients without recurrence. This difference was significant, but in contrast, 2 other studies have reported similar expressions of the HER2 receptor in recurrence and nonrecurrence groups. The P53 receptor follows the same pattern. Debled et al. (26) have reported p53 receptor expression in $17 \%$ of non-recurrence patients and $26.7 \%$ of recurrence patients with a significant difference, while Parmar's study (27) has reported a $17 \%$ and $20.3 \%$ expression rate of p53 receptor in non-recurrence and recurrence groups, respectively.

\subsection{Conclusions}

The aim of the present study was to evaluate diseasefree survival rates after surgery between BCT and MRM groups. Surgery type after neoadjuvant chemotherapy in patients with LABC cannot alter disease-free survival duration and recurrence rate. The role of HER2 and p53 receptors were significant in recurrence, which should be investigated in future studies. BCT in patients with LABC after neoadjuvant chemotherapy is allowed according to our findings and patients can benefit from its advantages in comparison to MRM.

\section{Acknowledgments}

This study was funded by Shahid Beheshti University of Medical Sciences.

\section{Footnotes}

Authors' Contribution: Mohammad Esmaeil Akbari, Belal Delshad and Mostafa Mousavizadeh contributed substantially to the conception and design of the study, the acquisition of data, or the analysis and interpretation. Mostafa Mousavizadeh and Belal Delshad drafted and provided critical revision of the article. Mohammad Esmaeil Akbari provided final approval of the version to publish.

Conflict of Interests: The authors declare that there is no conflict of interest.

Ethical Approval: Prior to enrollment, written informed consent was obtained from all subjects and Shahid Beheshti University of Medical Sciences Board of Ethics approved the protocol of the study. All procedures regarding human subjects were in accordance with the Helsinki Declaration guidelines.

Funding/Support: This study was funded by Shahid Beheshti University of Medical Sciences.

\section{References}

1. World Health Organization. The top 10 causes of death in 2004, fact sheet of WHO report. WHO; 2008.

2. World Health Organization. World cancer report 2008. 2008, [cited 2 January 2010]. Available from: http://www.iarc.fr/en/publications/ pdfsonline/wcr/2008/index.php.

3. Parkin DM, Bray F, Ferlay J, Pisani P. Global cancer statistics, 2002. CA CancerJClin.2005;55(2):74-108. doi:10.3322/canjclin.55.2.74. [PubMed: 15761078].

4. Anderson BO, Jakesz R. Breast cancer issues in developing countries: An overview of the Breast Health Global Initiative. World J Surg. 2008;32(12):2578-85. doi: 10.1007/s00268-007-9454-z. [PubMed: 18283512].

5. Sadjadi A, Nouraie M, Mohagheghi MA, Mousavi-Jarrahi A, Malekezadeh R, Parkin DM. Cancer occurrence in Iran in 2002, an international perspective. Asian Pac J Cancer Prev. 2005;6(3):35963. [PubMed: 16236000]. 
6. Mousavi SM, Gouya MM, Ramazani R, Davanlou M, Hajsadeghi $\mathrm{N}$, Seddighi Z. Cancer incidence and mortality in Iran. Ann Oncol. 2009;20(3):556-63. doi: 10.1093/annonc/mdn642. [PubMed: 19073863].

7. Goya M. Iranian Annual Cancer Registration Report 2005/2006. Ministry of Health and Medical Education, Health Deputy. Center for Disease Control and Prevention; 2007.

8. Garg PK, Prakash G. Current definition of locally advanced breast cancer. Curr Oncol. 2015;22(5):e409-10. doi: 10.3747/co.22.2697. [PubMed: 26628888]. [PubMed Central: PMC4608421].

9. Tryfonidis K, Senkus E, Cardoso MJ, Cardoso F. Management of locally advanced breast cancer-perspectives and future directions. Nat Rev Clin Oncol. 2015;12(3):147-62. doi: 10.1038/nrclinonc.2015.13. [PubMed: 25668732].

10. Kuerer HM, Singletary SE, Buzdar AU, Ames FC, Valero V, Buchholz TA, et al. Surgical conservation planning after neoadjuvant chemotherapy for stage II and operable stage III breast carcinoma. Am J Surg. 2001;182(6):601-8. doi: 10.1016/s0002-9610(01)00793-0. [PubMed: 11839324].

11. Vlastos G, Mirza NQ, Lenert JT, Hunt KK, Ames FC, Feig BW, et al. The feasibility of minimally invasive surgery for stage IIA, IIB, and IIIA breast carcinoma patients after tumor downstaging with induction chemotherapy. Cancer. 2000;88(6):1417-24. doi: 10.1002/(sici)10970142(20000315)88:6<1417::aid-cncr20>3.0.c0;2-1. [PubMed: 10717625].

12. Chawla A, Hunt KK, Mittendorf EA. Surgical considerations in patients receiving neoadjuvant systemic therapy. Future Oncol. 2012;8(3):23950. doi: 10.2217/fon.12.12. [PubMed: 22409461].

13. Nold RJ, Beamer RL, Helmer SD, McBoyle MF. Factors influencing a woman's choice to undergo breast-conserving surgery versus modified radical mastectomy. Am J Surg. 2000;180(6):413-8. doi: 10.1016/s0002-9610(00)00501-8. [PubMed: 11182389].

14. Lam WW, Fielding R, Ho EY, Chan M, Or A. Surgeon's recommendation, perceived operative efficacy and age dictate treatment choice by Chinese women facing breast cancer surgery. Psychooncology. 2005;14(7):585-93. doi: 10.1002/pon.877. [PubMed: 15546161].

15. Touboul E, Buffat L, Lefranc J, Blondon J, Deniaud E, Mammar $\mathrm{H}$, et al. Possibility of conservative local treatment after combined chemotherapy and preoperative irradiation for locally advanced noninflammatory breast cancer. Int J Radiat Oncol Biol Phys. 1996;34(5):1019-28. doi:10.1016/0360-3016(95)02207-4.

16. Touboul E, Lefranc JP, Blondon J, Buffat L, Deniaud E, Belkacemi Y, et al. Primary chemotherapy and preoperative irradiation for patients with stage II larger than $3 \mathrm{~cm}$ or locally advanced non-inflammatory breast cancer. Radiother Oncol. 1997;42(3):219-29. doi: 10.1016/s01678140(97)01923-3. [PubMed: 9155070].

17. Lerouge D, Touboul E, Lefranc JP, Genestie C, Moureau-Zabotto L, Blondon J. [Locally advanced non inflammatory breast cancer treated by combined chemotherapy and preoperative irradiation: Updated results in a series of 120 patients]. Cancer Radiother. 2004;8(3):155-67. French. doi: 10.1016/j.canrad.2004.01.001. [PubMed: 15217583].
18. Wolmark N, Wang J, Mamounas E, Bryant J, Fisher B. Preoperative chemotherapy in patients with operable breast cancer: Nine-year results from National Surgical Adjuvant Breast and Bowel Project B-18. J Natl Cancer Inst Monogr. 2001;(30):96-102. doi: 10.1093/oxfordjournals.jncimonographs.a003469. [PubMed: 11773300].

19. Ishitobi M, Ohsumi S, Inaji H, Ohno S, Shigematsu H, Akiyama F, et al. Ipsilateral breast tumor recurrence (IBTR) in patients with operable breast cancer who undergo breast-conserving treatment after receiving neoadjuvant chemotherapy: Risk factors of IBTR and validation of the MD Anderson Prognostic Index. Cancer. 2012;118(18):4385-93. doi: 10.1002/cncr.27377. [PubMed: 22252882].

20. Halverson KJ, Taylor ME, Perez CA, Myerson R, Philpott G, Simpson $\mathrm{JR}$, et al. Survival following breast-conserving surgery and irradiation or modified radical mastectomy in patients with invasive breast cancers with a maximum diameter of $1 \mathrm{~cm}$. Mo Med. 1993;90(12):759-63. [PubMed: 8145701].

21. Zhou X, Li Y. Local recurrence after breast-conserving surgery and mastectomy following neoadjuvant chemotherapy for locally advanced breast cancer - a meta-analysis. Breast Care (Basel). 2016;11(5):345-51. doi: 10.1159/000450626. [PubMed: 27920628]. [PubMed Central: PMC5123019].

22. Vergine M, Scipioni P, Garritano S, Colangelo M, Di Paolo A, Livadoti $\mathrm{G}$, et al. Breast-conserving surgery after neoadjuvant chemotherapy in patients with locally advanced cancer. Preliminary results. G Chir. 2013;34(9-10):254-6. [PubMed: 24629809]. [PubMed Central: PMC3926477].

23. Shenkier T, Weir L, Levine M, Olivotto I, Whelan T, Reyno L, et al. Clinical practice guidelines for the care and treatment of breast cancer: 15. Treatment for women with stage III or locally advanced breast cancer. CMAJ. 2004;170(6):983-94. doi: 10.1503/cmaj.1030944. [PubMed: 15023926]. [PubMed Central: PMC359433].

24. Heil J, Fuchs V, Golatta M, Schott S, Wallwiener M, Domschke $\mathrm{C}$, et al. Extent of primary breast cancer surgery: Standards and individualized concepts. Breast Care (Basel). 2012;7(5):364-9. doi: 10.1159/000343976. [PubMed: 24647774]. [PubMed Central: PMC3518938].

25. Sweeting RS, Klauber-Demore N, Meyers MO, Deal AM, Burrows EM, Drobish AA, et al. Young women with locally advanced breast cancer who achieve breast conservation after neoadjuvant chemotherapy have a low local recurrence rate. Am Surg. 2011;77(7):850-5. [PubMed: 21944346]. [PubMed Central: PMC4167782].

26. Debled M, MacGrogan G, Breton-Callu C, Ferron S, Hurtevent G, Fournier M, et al. Surgery following neoadjuvant chemotherapy for HER2-positive locally advanced breast cancer. Time to reconsider the standard attitude. Eur J Cancer. 2015;51(6):697-704. doi: 10.1016/j.ejca.2015.01.063. [PubMed: 25704790].

27. Parmar V, Krishnamurthy A, Hawaldar R, Nadkarni MS, Sarin R, Chinoy R, et al. Breast conservation treatment in women with locally advanced breast cancer - experience from a single centre. Int J Surg. 2006;4(2):106-14. doi: 10.1016/j.ijsu.2006.01.004. [PubMed: 17462324]. 